\title{
XLII.-Yellow Colouring Principles contained in Various Tannin Matters. Part VII. Arctostaphylos Uva ursi, Hamatoxylon Campeachianum, Rhus Metopium Myrica Gale, Coriaria myrtifolia, and Robinia pseudacacia.
}

By Anthur George Perkin, F.R.S.E.

THrs paper embodies the results which have been obtained from time to time during the past eighteen months in continuation of the investigation of the colouring matters associated with various tannins in plants (Trans., 1896, 69, 1289, 1299, 1303, ; 1897, 71, 1131, 1194 ; 1898, 73, $374,1016)$. The selection of each plant was suggested by some point of interest in connection with the tannin or colouring matter which a preliminary investigation indicated to be present, whereas the main work was undertaken to determine whether any general relationship exists between the tannin and colouring matter so frequently occurring together (Trans., 1897, 71, 1138).

In the earlier stages of this work, a relationship was noticed between the tannin and colouring matter co-existing in the plants which had been studied (Trans., 1897, 71, 1138), as both contained a similar nucleus. The exceptions brought to light during further investigation, however, are too numerous to allow of a rule being laid down on this point, although such a relationship is more usual than otherwise. It is probable that in some instances the plants contain both catechol and pyrogallol tannins, as is the case with the Quebracho Colorado (Trans., 
$1896,69,1306)$, and that some exceptions are only apparent. Such a mixture of tannins, however, does not occur in the Coriaria myrtifolia described below, as this contains only gallotannin, and it is evident that this substance and the co-existing quercetin do not possess similar nuclei. It is interesting to note that myricetin as yet is only known to be present in plants which also contain a gallotannin.

\section{Arctostaphylos Uva ursi.}

The Arctostaphylos Uva ursi, or bearberry, is found in Great Britain and throughout Northern Europe. The whole plant is astringent and has been employed for tanning leather. It contains arbutin (Kawalier, Annalen, 1852, 84, 356), ericolin (Kawalier, Jahresb., 1852, 685), and gallotannic acid (B. de Graffe, Amer. J. Pharm., 1896, 68, 313). In the present investigation, the leaves only were employed and were obtained by purchase from Merck of Darmstadt.

The yellow colouring matter was isolated by the method described in the case of Rhus Coriaric (Trans., 1896, 69, 1299). The crude product obtained in this manner was a mixture of the colouring matter with ellagic and gallic acid, the latter being derived from the gallotannin by the action of the acid employed in the operation. After washing with water, the residue was extracted with alcohol, and the ellagic acid which remained undissolved was identified by its dyeing properties and characteristic reaction with nitric and nitrous acids (Griessmayer, Annalen, 1871, 160, 55).

The alcoholic extract was evaporated to a small bulk, diluted with boiling water, and the precipitated colouring matter collected and crystallised from dilute alcohol. The yield was approximately $0.3 \mathrm{per}$ cent.

$$
\begin{gathered}
0.0972 \text { gave } 0.2110 \mathrm{CO}_{2} \text { and } 0.0313 \mathrm{H}_{2} \mathrm{O} . \quad \mathrm{C}=59.20 ; \mathrm{H}=3.57 . \\
\mathrm{C}_{15} \mathrm{H}_{10} \mathrm{O}_{7} \text { requires } \mathrm{C}=59.60 ; \mathrm{H}=3.31 \text { per cent. }
\end{gathered}
$$

The acetyl compound, $\mathrm{C}_{15} \mathrm{H}_{5} \mathrm{O}_{7}\left(\mathrm{C}_{2} \mathrm{H}_{3} \mathrm{O}\right)_{5}$, obtained as colourless needles, melted at $190-192^{\circ}$.

0.1153 gave $0.2416 \mathrm{CO}_{2}$ and $0.0410 \mathrm{H}_{2} \mathrm{O} . \mathrm{C}=58.21 ; \mathrm{H}=3.95$. $\mathrm{C}_{25} \mathrm{H}_{20} \mathrm{O}_{12}$ requires $\mathrm{C}=58.59 ; \mathrm{H}=3.90$ per cent.

Fusion of the colouring matter with alkali gave phloroglucinol and prolocatechuic acid; the latter, however, did not melt quite sharply, and appeared to contain a trace of a second acid.

This colouring matter differed from quercetin, with which it otherwise seemed to be identical, in the fact that dilute alkaline liquids dissolved it with a green coloration. Experiments were therefore undertaken to determine if the reaction was characteristic of the substance or due to impurity. 
The green colour was fugitive in character, and as it was possible that the second substance, by which it was presumably caused, might be more readily oxidised in this manner than the colouring matter, the alkaline solution was exposed in a shallow dish to the air, but the green colour did not disappear until the entire substance was decomposed.

The colouring matter was therefore converted into its monopotassium salt (Trans., 1899, 75, 438) and into its sulphate (Trans., 1895, $67,644)$, for these operations usually effect a removal of non-tinctorial impurities. The colouring matter regenerated from both compounds, however, still dissolved in alkaline solutions with a green coloration.

With a similar object, but also without success, some quantity of the substance was acetylated, and the product, after repeated crystallisation, decomposed in the usual manner.

$$
\begin{aligned}
& 2.7767 \text { gave } 1.6410 \mathrm{C}_{15} \mathrm{H}_{10} \mathrm{O}_{7} . \quad \mathrm{C}_{15} \mathrm{H}_{10} \mathrm{O}_{7}=59.09 . \\
& \mathrm{C}_{15} \mathrm{H}_{5} \mathrm{O}_{7}\left(\mathrm{O}_{2} \mathrm{H}_{3} \mathrm{O}\right)_{5} \text { requires } \mathrm{C}_{15} \mathrm{H}_{10} \mathrm{O}_{7}=58.98 \text { per cent. }
\end{aligned}
$$

These results pointed to the fact that the main bulk of the dye-stuff was quercetin, and as its abnormal behaviour with dilute alkali could be explained by the presence of a small quantity of myricetin, which is known to occur in numerous natural tannins, the action of bromine on the colouring matter was studied, the bromo-derivative of quercetin being distinguished from that obtained from myricetin by its sparing solubility in alcohol (Trans., 1896, 69, 1293). The substance made into a thin cream with acetic acid was treated with a slight excess of bromine and left for 48 hours. The greater part of the product crystallised in glistening needles melting at $243^{\circ}$ (found $\mathrm{C}=40.19 ; \mathrm{H}=2.96$; $\mathrm{C}_{15} \mathrm{H}_{8} \mathrm{O}_{7} \mathrm{Br}_{2}$ requires $\mathrm{C}=39.13 ; \mathrm{H}=1.74$ per cent.), and appeared to be dibromoquercetin, from which a trace of bromine had been eliminated during the purification. Dibromoquercetin, as Herzig has shown (Monatsh., 1897, 18, 700) is reconverted into quercetin by means of hydriodic acid, and the above product by this method gave a colouring matter which now dissolved in alkalis with a pure yellow colour, and had all the properties of pure quercetin (found $\mathrm{C}=59.27$; $\mathrm{H}=3.88$ per cent.).

The colouring matters of the leaves of Arctostaphylos Uva ursi are therefore ellagic acid and quercetin, tugether with a trace of a dyestuff soluble in dilute alkalis with a green coloration. The latter is probably myricetin, but this could not be definitely ascertained, owing to the small amount of raw material which the leaves contain.

Broach leaves (Trans., 1897, 73, 384), a South African tannin matter, have been shown to contain a colouring matter, $\mathrm{C}_{15} \mathrm{H}_{10} \mathrm{O}_{7}$, differing only from quercetin by the green colour of its alkaline solutions. There can be little doubt from the above results that this also 
is due to the presence of a second colouring matter, which is analogous to, or identical with, myricetin.

\section{The Leaves of Homatoxylon Campeachianum.}

For a supply of the leaves of this plant, I am much indebted to Mr. W. Fawcett, Director of Public Cardens and Plantations, Kingston, Jamaica. They were examined for the presence of a colouring matter, in case this should be chemically related to the hæmatoxylin, which is present in the stem. The isolation of a yellow dye-stuff rendered such a relationship unlikely, but the work was continued in order to study a tannin which was present in some quantity. The dye-stuff was obtained as yellow needles soluble in dilute alkalis with a green coloration.

$$
\begin{gathered}
0.1164 \text { gave } 0.2540 \mathrm{CO}_{2} \text { and } 0.0392 \mathrm{H}_{2} \mathrm{O} . \quad \mathrm{C}=59.51 ; \mathrm{H}=3.74 . \\
\mathrm{C}_{15} \mathrm{H}_{10} \mathrm{O}_{7} \text { requires } \mathrm{C}=59.60 ; \mathrm{H}=3.31 \text { per cent. }
\end{gathered}
$$

The acetyl derivative, $\mathrm{C}_{15} \mathrm{H}_{5} \mathrm{O}_{7}\left(\mathrm{C}_{2} \mathrm{H}_{3} \mathrm{O}\right)_{5}$, melted at $190^{\circ}$.

0.1056 gave 0.2258 and $0.0410 \mathrm{H}_{2} \mathrm{O} . \mathrm{C}=58.31 ; \mathrm{H}=4.31$.

$$
\mathrm{C}_{25} \mathrm{H}_{20} \mathrm{O}_{12} \text { requires } \mathrm{C}=58.59 ; \mathrm{H}=3.90 \text { per cent. }
$$

The main products of the action of fused alkali on the colouring matter were phloroglucinol and protocatechuic acid. The substance therefore appeared to be quercetin, accompanied, like that contained in the bearberry leaves, by myricetin in small quantity. On treatment with bromine, the bulk of the product crystallised from alcohol in yellow needles melting at $232-234^{\circ}$, and the colouring matter re. generated from this by means of hydriodic acid dissolved in alkalis with a yellow colour, and had the reactions of pure quercetin.

The Tannin.-The leaves were extracted with boiling alcohol, the extract evaporated to a small bulk, poured into water, and the mixture treated with ether in order to remove wax and chlorophyll. From the brown aqueous liquid, after saturation with salt, the tannin was extracted with ethyl acetate, and the solution cautiously evaporated. The viscous residue was dissolved in water, and salt added, causing the precipitation of a brown impurity, which was removed by agitation with bibulous paper and filtration. By subsequent extraction with ethyl acetate, the tannin was obtained as a yellow, friable mass.

0.1182 gave $0.2304 \mathrm{CO}_{2}$ and $0.0428 \mathrm{H}_{2} \mathrm{O} . \mathrm{C}=53.15 ; \mathrm{H}=4.02$ per cent.

Digested with boiling dilute sulphuric acid, it yielded gallic acid, obtained as needles melting at $238-240^{\circ}$. As it further gave a bluish-green coloration with aqueous ferric chloride, but no precipitate with bromine water, it was identified as gallotannic acid. 
Professor H. E. Procter was good enough to undertake an examina. tion of the tanning properties of the leares, and $I$ am indebted to him for the following account of his results :

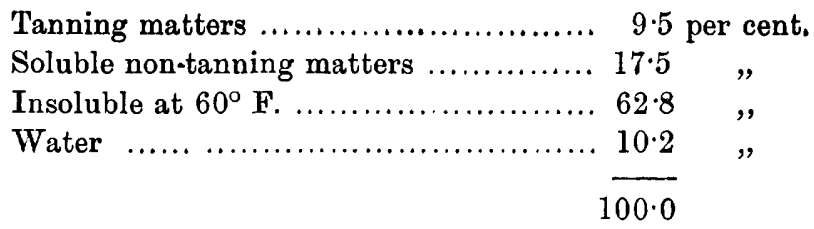

"The tanning strength, $9 \cdot 5$ per cent., is too low to allow of the profitable exportation of the leaves as such, but the colour of the leather tanned by them is by no means bad, and if a satisfactory extract of not less than 25 per cent. strength can be produced from them, it would no doubt find a market in this country."

According to Mr. W. Fawcett, the sample of leaves employed in this investigation was of somewhat poor quality, owing to collection late in the season. It is probable that at an earlier period they contain more tannin, for an analysis of selected leaves gave 11.2 per cent. of tanning matter.

\section{Rhus Metopium.}

I am also indebted to Mr. W. Fawcett for samples of the stems and leaves of this plant. Its comparison with $R$. Cotinus and $R$. rhodanthema was of interest, because the leaves of the latter contain a colouring matter which is distinct from that of the stem (Trans., 1897, 71, 1016). Beyond a trace of ellagic acid, the stem of $R$. Metopium is devoid of colouring matter, and from an examination of other members of this class, the properties of $R$. Cotinus and $R$. rhodanthema in this respect appear to be somewhat exceptional.

The colouring matter of the leaves was obtained in the form of yellow needles soluble in alkaline solutions with a deep green coloration, and seemed to be myricetin, but further experiment revealed the presence of two substances. Thus the acetyl compound had no definite melting point, and, on analysis, gave numbers $(\mathrm{C}=57.25 ; \mathrm{H}=4.51$ per cent.) intermediate between those required by acetylmyricetin and acetylquercetin. To separate as far as possible the constituents of the mixture, this acetyl compound was fractionally crystallised from alcohol, and in this way a less soluble portion was eventually obtained which had the properties of acetylmyricetin, $\mathrm{C}_{15} \mathrm{H}_{4} \mathrm{O}_{8}\left(\mathrm{C}_{2} \mathrm{H}_{3} \mathrm{O}\right)_{6}$, and melted at $204-206^{\circ}$.

0.1055 gave $0.2200 \mathrm{CO}_{2}$ and $0.0396 \mathrm{H}_{3} \mathrm{O} . \quad \mathrm{C}=56.87 ; \mathrm{H}=4 \cdot 17$. $\mathrm{C}_{27} \mathrm{H}_{22} \mathrm{O}_{14}$ requires $\mathrm{C}=56.84 ; \mathrm{H}=3.86$ per cent. 
A portion was hydrolysed with acid, and the regenerated colouring matter analysed :

$$
\begin{gathered}
0.0953 \text { gave } 0.1993 \mathrm{CO}_{2} \text { and } 0.0305 \mathrm{H}_{2} \mathrm{O} . \quad \mathrm{C}=57.03 ; \mathrm{H}=3.54 . \\
\mathrm{C}_{15} \mathrm{H}_{10} \mathrm{O}_{\mathrm{S}} \text { requires } \mathrm{C}=56.60 ; \mathrm{H}=3.14 \text { per cent. }
\end{gathered}
$$

It was obtained as glistening, yellow needles, and had the characteristic reactions of myricetin. The amount present in the leaves is approximately 0.1 per cent.

The identification with certainty of the second colouring matter was more difficult, for it was by far the minor constituent of the mixture. From the more soluble portion of the mixed acetyl derivatives, a fraction was obtained melting at $189-191^{\circ}$, which appeared to be acetylquercetin, but the colouring matter regenerated by hydrolysis with acid proved to contain a trace of myricetin. It was therefore treated with bromine, and a compound was thus obtained which melted at $237-239^{\circ}$, and was evidently dibromoquercetin. Quercetin is therefore the second colouring matter of the leaves of $R$. Metopium, and its identity was further confirmed by the presence of protocatechuic acid among the products formed by the action of fused alkali on the mixed colouring matters. On account of their small quantity, the above products could not be analysed.

In their colouring matters, the leaves of the Rhus Metopium resemble those of $R$. Cotinus, $R$. rhodanthema, and $R$. Coriaria previously examined, which contain respectively myricetin, quercetin, and myricetin.

According to the late Professor Henry Trimble, the leaves of $R$. metopium contain gallotannic acid. An analysis gave the following result :

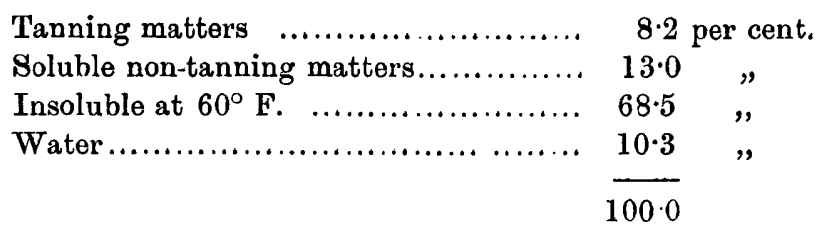

Coriaria myrtifolia.

Coriaria myrtifolia is a low, deciduous shrub, native of Southern Europe, and is emplcyed in dyeing black. It has been examined by Riban (Zeit. Chem., 1867, 663), who isolated from it the poisonous glucoside, coriamyrtin. For a supply of the leaves, I am much indebted to the kindness of Professor Maxime Cornu, of the Museum d'Histoire Naturelle, at Paris. The crude yellow colouring matter, isolated in the usual manner, contained ellagic acid, which, on extraction with alcohol, remained undissolved, and was identified by the usual tests. 
The alcoholic extract was evaporated to a small bulk and diluted with boiling water, and the colouring matter which thus separated was collected and crystallised from dilute alcohol. It formed glistening, yellow needles soluble in alkaline solutions with a yellow colour.

$$
\begin{gathered}
0.1126 \text { gave } 0.2456 \mathrm{CO}_{2} \text { and } 0.0350 \mathrm{H}_{2} \mathrm{O} . \quad \mathrm{C}=59.48 ; \mathrm{H}=3.45 . \\
\mathrm{C}_{15} \mathrm{H}_{10} \mathrm{O}_{7} \text { requires } \mathrm{C}=59.60 ; \mathrm{H}=3.31 \text { per cent. }
\end{gathered}
$$

The acetyl compound, $\mathrm{C}_{15} \mathrm{H}_{5} \mathrm{O}_{7}\left(\mathrm{C}_{2} \mathrm{H}_{3} \mathrm{O}\right)_{5}$, was obtained as colourless needles melting at $191^{\circ}$.

0.1135 gave $0.2421 \mathrm{CO}_{2}$ and $0.0450 \mathrm{H}_{2} \mathrm{O} . \mathrm{C}=58.17 ; \mathrm{H}=4.40$.

$$
\mathrm{C}_{25} \mathrm{H}_{20} \mathrm{O}_{12} \text { requires } \mathrm{C}=58.59 ; \mathrm{H}=3.90 \text { per cent. }
$$

As fusion with alkali gave phloroglucinol and protocatechuic acid, this colouring matter was evidently quercetin.

The tannin of this plant is known to be gallotannic acid, and evidence of this was forthcoming by the isolation of much gallic acid during the extraction of the scolouring matter. An analysis, carried out under the direction of Professor Procter, gave the following result :

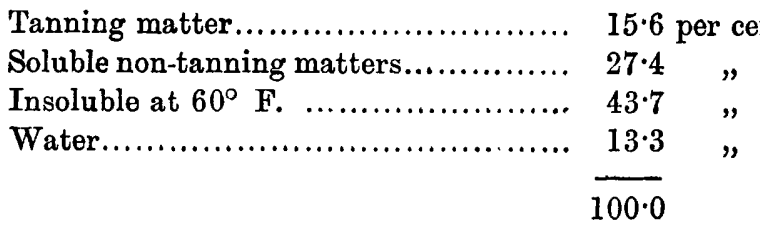

The colour of leather tanned by these leaves is very satisfactory, and practically equal to that produced by genuine sumach (R. Coriaria); the strength in tanning matter, however, is considerably inferior, good samples of sumach reaching 25 and even 30 per cent. of this material.

\section{Myrica Gale.}

Though it has been shown that myricetin exists in numerous plants, with the exception of the Myrica Nagi, which is difficult to obtain, the quantity present in each is so very small that its further examination has been of necessity postponed until a more fruitful source is discovered. With the latter object $M$. Gale, the ordinary bog-myrtle, was examined, in the hope that it might contain some quantity of the colouring matter. For a supply of the bark and leaves, I am indebted to the kindness of Professor J. J. Hummel.

The colouring matter of the leaves was obtained as glistening, yellow needles, soluble in alkalis with a green coloration. The yield was approximately 0.1 per cent.

Found $\mathrm{C}=56.57 ; \mathrm{H}=3.69$.

$\mathrm{C}_{15} \mathrm{H}_{10} \mathrm{O}_{8}$ requires $\mathrm{C}=56.60 ; \mathrm{H}=3.14$ per cent.

VOI. LXXVII. 
The acetyl compound, $\mathrm{C}_{15} \mathrm{H}_{4} \mathrm{O}_{8}\left(\mathrm{C}_{2} \mathrm{H}_{3} \mathrm{O}\right)_{6}$, formed colourless needles melting at $204-206^{\circ}$.

Found $\mathrm{C}=56.57 ; \mathrm{H}=3.86$.

$$
\mathrm{C}_{27} \mathrm{H}_{22} \mathrm{O}_{14} \text { requires } \mathrm{C}=56.84 ; \mathrm{H}=3.86 \text { per cent. }
$$

On fusion with alkali, phloroglucinol and an acid resembling gallic acid were obtained; the colouring matter was therefore myricetin, but although the result is interesting, in that it confirms the conclusions of the botanist, $M$. Gale cannot be employed as a source of this colouring matter in quantity. The bark was almost devoid of dyeing properties, but appeared to contain a gallotannin.

The experiments on this plant were largely carried out by Mr. I. E. J. Wilkinson, to whom my best thanks are due.

\section{The Leaves of Robinia pseudacacia.}

The Robinia pseudacacia (common or false acacia, North American locust) is a native of the United States, from Pennsylvania southward to Carolina, where its timber is extensively employed. It is also cultivated in France. The flowers have been examined by $\mathrm{Z}$ wenger and Dronke (Annalen, Suppl., 1861, 1, 257), who isolated from them a quercetin glucoside, robinin, which differed from quercitrin in yielding no precipitate with lead acetate. For a liberal supply of the bark, stem, and leaves, I am much indebted to Dr. M. Jarry of Paris.

A boiling aqueous decoction of the leaves was treated with basic lead acetate solution, and the resulting pale yellow precipitate suspended in water and decomposed with boiling dilute sulphuric acid. From the clear liquid decanted from the lead sulphate, the colouring matter was removed by extraction with ether and purified by crystallisation from dilute alcohol. The jield was 0.14 per cent. of the crude substance, and this, on purification, was reduced approximately by one-half.

$$
\begin{gathered}
0.0969 \text { gave } 0.2412 \mathrm{CO}_{2} \text { and } 0.0442 \mathrm{H}_{2} \mathrm{O} . \quad \mathrm{C}=67.88 ; \mathrm{H}=5.06 . \\
0.1126 \quad 0.2787 \mathrm{CO}_{2} \Rightarrow \quad 0.0490 \mathrm{H}_{2} \mathrm{O} . \quad \mathrm{C}=67.49 ; \mathrm{H}=4.84 . \\
\mathrm{C}_{16} \mathrm{H}_{12} \mathrm{O}_{5} \text { requires } \mathrm{C}=67.60 ; \mathrm{H}=4.22 \text { per cent. }
\end{gathered}
$$

This new colouring matter, for which the name acacetin is proposed, forms almost colourless needles, soluble in alkalis with a pale yellow coloration. With alcoholic lead acetate, it yields a yellow precipitate, but owing to the instability of this compound in the presence of dilute acetic acid, it is not entirely precipitated in this manner. It does not yield a salt with potassium acetate, or compounds with mineral acids, and the inference that it does not contain hydroxyl groups in relatively ortho-positions is also borne out by its feeble dyeing properties. With 
sulphuric acid, it gives a pale yellow solution, and with alcoholic ferric chloride a deep reddish-brown coloration.

The acetyl derivative, $\mathrm{C}_{16} \mathrm{H}_{10} \mathrm{O}_{5}\left(\mathrm{C}_{2} \mathrm{H}_{3} \mathrm{O}\right)_{2}$, formed colourless needles melting at $195-198^{\circ}$, and is sparingly soluble in alcohol.

0.1002 gave $0.2373 \mathrm{CO}_{2}$ and $0.0390 \mathrm{H}_{2} \mathrm{O} . \quad \mathrm{C}=64.58 ; \mathrm{H}=4.32$. $\mathrm{C}_{20} \mathrm{H}_{18} \mathrm{O}_{7}$ requires $\mathrm{C}=65.21 ; \mathrm{H}=4.35$ per cent.

By decomposition with fused alkali, acacetin yielded phloroglucinol, and an acid melting at $210^{\circ}$ having the reactions of $\mathrm{p}$-hydroxybenzoic acid. In the crude condition, the latter was contaminated with a trace of a second acid, which gave with aqueous ferric chloride a green coloration, and appeared to be protocatechuic acid. The colouring matter contained one methoxy-group.

0.1414 gave $0.1085 \mathrm{AgI} . \mathrm{CH}_{3}=4.89$.

$$
\mathrm{C}_{15} \mathrm{H}_{9} \mathrm{O}_{4}\left(\mathrm{O} \cdot \mathrm{CH}_{3}\right) \text { requires } \mathrm{CH}_{3}=5 \cdot 28 \text { per cent. }
$$

The hydriodic acid left in the distilling flask in this determination was poured into a solution of sodium hydrogen sulphite, and the precipitate collected and purified by crystallisation from dilute alcohol.

0.1075 gave $0.2615 \mathrm{CO}_{2}$ and $0.0390 \mathrm{H}_{2} \mathrm{O} . \quad \mathrm{C}=66.34 ; \mathrm{H}=4.03$. $\mathrm{C}_{15} \mathrm{H}_{10} \mathrm{O}_{5}$ requires $\mathrm{C}=66.66 ; \mathrm{H}=3.70$ per cent.

The product was obtained as almost colourless needles, soluble in alkalis with a pale yellow coloration. With alcoholic ferric chloride, a deep reddish-brown liquid was obtained, and these reactions, together with its dyeing properties, indicated its identity with apigenin, the colouring matter of parsley (Trans., 1897, 71, 805). This conclusion is in harmony with all the results of the investigation, and there can be little doubt that acacetin is a monomethyl ether of apigenin. The amount of acacetin available for this work was only 2 grams, consequently a further characterisation of the apigenin was impossible. When a new supply of raw material can be obtained, this colouring matter will be further studied.

It is interesting to note that whereas an apigenin monomethyl ether, as a glucoside, is contained in the leaves of this plant, a quercetin glucoside occurs in the flowers (Zwenger and Dronke, loc. cit.), quercetin being probably a dihydroxyapigenin. If opportunity occurs, a reinvestigation of robinin will be undertaken.

The stem and bark of Robinia pseudacacia are devoid of colouring matter.

Tanning Properties.-The following analyses of the leaves and the bark were carried out under the direction of Professor Procter : 


\begin{tabular}{|c|c|c|c|}
\hline Tanning matters ... & $\begin{array}{c}\text { Leaves. } \\
8 \cdot 2\end{array}$ & $\begin{array}{c}\text { Bark. } \\
2 \cdot 8\end{array}$ & cent. \\
\hline Soluble non-tanning matters ... & $9 \cdot 5$ & $12 \cdot 8$ & , \\
\hline Insoluble in water at $60^{\circ} \mathrm{F} \ldots \ldots$. & $73 \cdot 4$ & $75 \cdot 3$ & $"$ \\
\hline \multirow[t]{2}{*}{ Water $\ldots \ldots \ldots \ldots \ldots \ldots \ldots \ldots \ldots$} & $8 \cdot 9$ & $9 \cdot 1$ & $"$ \\
\hline & 0.0 & $00 \cdot 0$ & \\
\hline
\end{tabular}

The leaves contain too small an amount of tannin to be of much value as a tanning material, and the bark is practically worthless in this respect. Qualitative tests indicated the absence of tannin in the stem of the plant.

The author is indebted to the Research Fund Committee of the Chemical Society for a grant which has been in part employed for expenses of this investigation.

Clothworkers' Researoh Laboratory,

Dyeing Department,

YoRZSHIRE COLLEGE. 